\title{
Clinical Questions and an Inquiring Mind for Patients with IgG4-related Disease
}

\author{
Motohisa Yamamoto and Hiroki Takahashi
}

Key words: IgG4-related disease, inquiring mind, retroperitoneal fibrosis

(Intern Med 58: 469-470, 2019)

(DOI: 10.2169/internalmedicine.1765-18)

Immunoglobulin (Ig)G4-related disease (IgG4-RD) is a new disease entity that was established in Japan in this century. This chronic fibro-inflammatory disorder is characterized by elevated levels of serum IgG4 and abundant infiltration of IgG4-bearing plasma cells with fibrosis. Various organs can be involved, including the lacrimal and salivary glands, pancreas, bile duct, kidneys, retroperitoneal cavity, lungs, aorta, pituitary gland, thyroid gland, and prostate gland (1). Before the establishment of this disorder, lesions of the lacrimal and salivary glands were usually diagnosed as Sjögren's syndrome (2), and pancreatic lesions were often diagnosed as pancreatic cancer and treated surgically. However, regarding pancreatic lesions, lymphoplasmacytic sclerosing pancreatitis was proposed based on the histopathological findings described by Kawaguchi et al. (3), and autoimmune pancreatitis was proposed from clinical findings by Yoshida et al. (4) in the 1990s. Lacrimal and salivary gland lesions were noticed to be different from typical Sjögren's syndrome $(5,6)$. In 2000 , elevated levels of serum IgG4 were detected in autoimmune pancreatitis by Hamano et al. (7), and the same group found prominent infiltration of IgG4-positive plasmacytes in the involved organs the following year (8). This was the beginning of IgG4-RD. The lacrimal and salivary gland involvement were later revealed to be quite different from Sjögren's syndrome (9). The new disease entity was subsequently proposed as IgG4-related autoimmune disease by Kamisawa et al. (10), IgG4-positive multiorgan lymphoproliferative syndrome by Masaki et al. (11), and systemic IgG4-related plasmacytic syndrome (SIPS) by our group (12). Only 18 years ago, these disease concepts were unified under the term IgG4-RD.

I read both the paper by Konno et al. (13) and the case report from 35 years ago (14) with interest and excitement. They impressed me. The diagnosis for the case 35 years ago was not, of course, IgG4-RD. At present, IgG4-RD is relatively easy to diagnose based on the typical clinical find- ings: enlargement of the submandibular gland; periaortitis; and hydronephrosis due to left ureteral obstruction. However, the mesenteric vein obstruction and central diabetes insipidus were very interesting findings, even now.

Certainly, the authors seemed to have felt uncomfortable with the diagnosis of this case. That is why it is worth noting that this clinical question was solved 35 years later. Scientists, including physicians, must always have a degree of intellectual modesty and an inquiring mind. The description in the textbook at hand will not necessarily be considered correct in the future. Current medical knowledge is imperfect, and there is a constant need to review our own understanding. We are always striving to provide patients with the best treatment based on the latest knowledge. If questions remain that cannot be resolved even using the latest medical knowledge, the issues involved need to be kept in mind. Time will pass and new findings may provide insights that will solve them. The authors continued to keep their clinical question in mind and took action 35 years later. This diagnostic process gave me a feeling of excitement and led me to remember the scientific ideal. The humility and spirit of inquiry the authors show are indispensable for doctors. In particular, I recommend that young doctors and researchers read this paper, and hopefully keep the lessons provided in their minds.

The authors state that they have no Conflict of Interest (COI).

\section{References}

1. Umehara H, Okazaki K, Masaki Y, et al. A novel clinical entity, IgG4-related disease (IgG4RD): general concept and details. Mod Rheumatol 22: 1-14, 2012.

2. Morgan WS, Castleman B. A clinicopathologic study of Mikulicz's disease. Am J Pathol 29: 471-503, 1953.

3. Kawaguchi K, Koike M, Tsuruta K, et al. Lymphoplasmacytic sclerosing pancreatitis with cholangitis: a variant of primary scle- 
rosing cholangitis extensively involving pancreas. Hum Pathol 22: 387-395, 1991

4. Yoshida K, Toki F, Takeuchi T, et al. Chronic pancreatitis caused by an autoimmune abnormality. Proposal of the concept of autoimmune pancreastitis. Dig Dis Sci 40: 1561-1568, 1995.

5. Suzuki S, Kida S, Ohira Y, et al. A case of Sjögren's syndrome accompanied by lymphadenopathy and IgG4 hypergammaglobulinemia. Ryumachi 33: 249-254, 1993.

6. Yamamoto M, Takahashi $\mathrm{H}$, Mizukoshi $\mathrm{T}$, et al. A male case of Sjögren's syndrome presented with generalized lymphadenopathy and swelling of both lacrimal and salivary glands which responded remarkably well to an administration of corticosteroids. Nihon Rinsho Meneki Gakkai Kaishi (Jpn J Clin Immunol) 23: 22-29, 2000 (in Japanese, Abstract in English).

7. Hamano H, Kawa S, Horiuchi A, et al. High serum IgG4 concentration in patients with sclerosing pancreastitis. N Engl J Med 344: 732-738, 2001

8. Hamano H, Kawa S, Ochi Y, et al. Hydronephrosis associated with retroperitoneal fibrosis and sclerosing pancreatitis. Lancet 359: 1403-1404, 2002.

9. Yamamoto M, Harada S, Ohara M, et al. Clinical and pathological differences between Mikulicz's disease and Sjögen's syndrome.
Rheumatology (Oxford) 44: 227-234, 2005.

10. Kamisawa T, Funata N, Hayashi Y, et al. A new clinicopathological entitiy of IgG4-related autoimmune disease. J Gastroenterol 38: 982-984, 2003.

11. Masaki Y, Dong L, Kurose K, et al. Proposal for a new clinical entitiy, IgG4-positive multiorgan lymphoproliferative syndrome: analysis of 64 cases of IgG4-related disorders. Ann Rheum Dis 68: 1310-1315, 2009.

12. Yamamoto $M$, Takahashi $H$, Suzuki $C$, et al. A new conceptuallyzation for Mikulicz's disease as a systemic IgG4-related plasmacytic syndrome (SIPS). Scand J Rheumatol Suppl 123: 38, 2007.

13. Konno S, Matsuno Y, Ichimiya S, et al. Retroperitoneal fibrosis diagnosed as IgG4-related disease after 35 years. Intern Med 58: 609-613, 2019.

14. Oguma $Y$, Nishimura $M$, Abe $S$, et al. A case of retroperitoneal fibrosis following dihydroergotamine therapy. Nihon Naika Gakkai Zasshi (J Jpn Soc Int Med) 73: 864-870, 1984 (in Japanese).

The Internal Medicine is an Open Access journal distributed under the Creative Commons Attribution-NonCommercial-NoDerivatives 4.0 International License. To view the details of this license, please visit (https://creativecommons.org/licenses/ by-nc-nd/4.0/).

(C) 2019 The Japanese Society of Internal Medicine Intern Med 58: 469-470, 2019 